\title{
Designing Optimal Benefit Rules for Flexible Retirement*
}

\author{
Péter Eső \\ Kellogg School of Management, MEDS department, \\ Northwestern University \\ 2001 Sheridan Rd., Evanston, IL 60208 \\ email: eso@kellogg.northwestern.edu \\ and \\ András Simonovits \\ Institute of Economics, Hungarian Academy of Sciences, \\ also CEU, and Budapest University of Technology and Business \\ 1112 Budapest, Budaörsi út 45, Hungary \\ email: simonov@econ.core.hu
}

September 1, 2002

\footnotetext{
*We express our debt to Peter Diamond, who has kindly sent us a copy of his unpublished book (Diamond, 2001) and has made useful remarks on a related work of András Simonovits. The second author also acknowledges the financial support of the Hungarian Science Foundation OTKA T 037383 and of the OKTK.
} 


\title{
Designing Optimal Benefit Rules for Flexible Retirement
}

\author{
by \\ Péter Eső \\ and \\ András Simonovits
}

\begin{abstract}
This paper applies the techniques of mechanism design to find an optimal nonlinear pension benefit rule for flexible old-age retirement. We assume that individuals have private information regarding their expected lifespans. The government's goal is to design a pension system (a payroll tax and a function relating benefits to employment length), which maximizes a social welfare function and satisfies a social budget constraint. Since individuals with different expected lifespans optimize their employment lengths conditional on the benefit function, the government must also take into account incentive constraints.

We characterize the solution to this problem for various social welfare functions. Under utilitarianism, the solution is a completely inflexible system, where all individuals retire at the same age with the same (yearly) benefits; and, surprisingly, the first-best (complete information) aggregate welfare is attained. If the social welfare function is strictly concave, then individuals with shorter expected lifespans retire earlier with benefits lower than those in the first-best. In the optimal pension system, individuals with shorter expected lifespans subsidize those who expect to live longer. We also compute the optimal benefit rule for several specifications with CRRA utility functions and realistic parameter values, and discuss the numerical results.
\end{abstract}

Keywords: flexible retirement, asymmetric information, actuarial fairness, mechanism design

JEL Classification: D82, D91 and H55 


\section{Introduction}

Increasing life expectancy notwithstanding, people retire earlier nowadays than they did decades ago. For example, Coile and Gruber (2000) report that $81 \%$ of the 62 year old US male cohort worked in 1950, and this ratio dropped to $51 \%$ by $1995 .{ }^{1}$ A common explanation for this phenomenon is that pension benefit rules are poorly designed in many countries (Stock and Wise, 1990; Samwick, 1999; Gruber and Wise, eds., 1999), which, among other things, endangers the sustainability of social security systems. It is therefore an important social task to improve pension benefit rules so that social security systems remain feasible (by, for example, increasing retirement age), while other goals, such as insurance, fairness, and the accommodation of heterogeneous individual characteristics, are also attained.

In this paper, we consider the problem of designing optimal flexible pension benefit rules under the assumption that individuals have private information regarding their expected lifespans. The government's goal is to design a pension system (a payroll tax or contribution and a function relating benefits to employment length), which maximizes a social welfare function and satisfies a social budget constraint. Since individuals with different expected lifespans optimize their employment lengths conditional on the benefit function, the government must also take into account incentive constraints. We will use techniques familiar from optimal mechanism design, in particular, optimal income taxation pioneered by Mirrlees (1971), to find the optimal solution to the government's problem.

Some of our (preliminary and incomplete) findings confirm the intuition of classic mechanism design models (e.g., we find "no distortion at the top"), but we also obtain surprising results. For example, if the social welfare function is utilitarian, then the solution to the government's second-best problem is a completely inflexible system, which makes every individual retire at the same age with the same yearly benefits, but attains the first-best (complete information) aggregate welfare. If the social welfare function is strictly concave, then individuals with shorter expected lifespans retire earlier with benefits that are lower than those in the first-best.

In the pension literature, Diamond and Mirrlees (1978) were the first to study mechanism design problems, namely, concerning disability benefits. However, the bulk of the literature has confined attention to models where heterogeneity is present in individual preferences (the disutility of labor), and overlooked other important aspects, like the heterogeneity and asymmetric information regarding individual lifespans. One recent and notable exception is the book of Diamond (2001), where several models are analyzed, including one with heterogeneity in individual lifespans. Independently of his work, one of the authors also proposed

\footnotetext{
${ }^{1}$ In the US, the normal retirement age is 65 , while the minimum retirement age is 62 .
} 
a model (Simonovits, 2001) where individuals know their own expected lifespans and elasticities for leisure and the government only knows their distribution. That paper proposed the dampening of incentives in the traditional fair benefit rule and alluded to the possibility of solving the problem by optimal mechanism design, a task that we carry out in the present paper. We explain how our approach and results differ from those of the literature below.

Under the assumptions (usual in the literature, but different from those of the present paper) that the government and the individuals have the same information regarding expected lifespans, and that asymmetric information pertains to the individuals' disutilities of labor, the optimal benefit rule is the actuarially fair schedule, $b^{F}(R)=\tau R /(m-R)$ where $R$ is retirement age, $\tau$ is the social security payroll tax, $m$ is the expected lifespan of all individuals, and $b^{F}(R)$ is the yearly benefit of a pensioner retiring at age $R$. Under this benefit rule, workers who prefer leisure more retire earlier and receive yearly benefits corresponding to their lifetime contributions and to their remaining lifespan. ${ }^{2}$

If there is indeed no asymmetric information regarding expected lifespans, then the actuarially fair schedule is optimal (Börsch-Supan, 2001). However, if some individuals know that their expected lifetime is longer than the average, then they can retire later (closer to $m$ ) and enjoy disproportionately high benefits for the rest of their lives. Therefore the actuarially fair benefit schedule may not be sustainable when individuals have private information regarding their expected lifespans.

The logic of traditional fairness is undermined by the strong positive relationship between the individual lifespan and the individual length of employment (those living longer also work longer). This positive correlation is established empirically by Waldron (2001), and modelled by Gruber and Orszag (1999), Simonovits (1999), and Guegano (2000). An indirect (and disputed) argument for the possibility of individuals anticipating their lifespans is provided by the wellknown fact that the age-specific mortality rates of people buying private annuities are significantly lower that those of the general population (Friedmann and Warshawski, 1990).

In chapters 6 and 7 of Diamond (2001), a model where individuals have private information regarding their lifespan is considered and the optimal benefit rule is derived where individuals are allowed to retire at two different pre-specified ages. Our approach is similar to this except that we allow for a continuum of retirement ages. On the other hand, we simplify the setup by assuming that all individuals have the same disutility of labor. In a related paper, Simonovits (2002) considers a case where both individual lifespans and labor disutilities are heterogeneous but restricts the analysis to the special case of linear benefit functions.

Our main contribution to the existing literature on pension system reforms is to

\footnotetext{
${ }^{2}$ With no discounting, an individual's contributions equal the benefits $\mathrm{s} /$ he receives, $\tau R=$ $b^{F}(R)(m-R)$.
} 
extend the analysis of optimal pension benefit rules in an important new direction, by assuming that individuals have private information regarding their expected lifespans. We analytically derive the equations that determine the optimal secondbest benefit rule. This benefit rule appears to be very much different from the actuarially fair schedule (which would be optimal if individuals differed in their disutilities of labor, but not in their expected lifespans). The socially optimal and incentive compatible benefit rule leads to a redistribution from individuals with shorter expected lifespans to individuals with longer expected lifespans. ${ }^{3}$ The properties of the optimal benefit rule depend on the shape of the social welfare function: more egalitarian social objectives lead to more flexible benefit rules.

We also compute the optimal benefit rule using realistic parameter values. Figures 1.a-d illustrate the results for the case when individual expected lifespans (starting at age 20, when the individual enters the work force) are uniformly distributed between 49 and 59 (working) years, and the payroll tax is 20 percent. The numerical results confirm that the optimal benefit rule is less steep than the fair schedule (see Figure 1.d). ${ }^{4}$ The optimal benefit rule can be convex or concave depending on the parameter values.

The structure of the paper is as follows: Section 2 presents the model. Sections 3 and 4 derive the first-best and the second-best solutions, respectively. Section 5 outlines the algorithm for numerical solution and Section 6 is devoted to simulation. Section 7 concludes.

\section{The Model}

In the present version of the paper we analyze the following problem. There is a (stationary) population of individuals who have private information regarding their expected lifespan (denoted by $t$ ). Every individual enters the labor market at age 0 , and produces 1 unit of goods per year while he or she is active, 0 when he or she is inactive (retired or dead). As usual in models of old-age pension systems, we assume that workers cannot save for retirement. ${ }^{5}$

The pension systems we consider will be realistic in the following aspects. The first ingredient of a pension scheme is a yearly social security payroll tax, $\tau<1$,

\footnotetext{
${ }^{3}$ Under asymmetric information regarding individual lifespans, every incentive compatible benefit rule provides such redistribution, and so does the unraveling fair benefit rule, too.

${ }^{4}$ Note that this observation is similar to the one made by Diamond and Mirrlees (1986, p. 27) in the context of disability insurance: "optimal benefits rise with the age of retirement but more slowly than would be actuarially fair."

${ }^{5}$ The reasons for the lack of adequate retirement savings are that goods are perishable, private retirement annuities are expensive (due to the asymmetric information problem investigated here), or agents are short sighted. In the model, we could use either of the first two explanations, so there is a need for a well-designed pension system.
} 
which is levied on active workers (we assume away other taxes). When a worker retires (say, at age $R$ ), he or she stops producing goods and paying the tax, and receives a yearly retirement benefit, $b>0$, until he or she dies. The government designs the tax rate, $\tau$, and the benefit schedule as a function of the time of retirement, $b(R)$. We require that the pension system be financially sound (the expected benefit payments cannot exceed the amount of social security taxes paid in). We do not allow the pension system to cut off or reduce the benefits of individuals over time, or give out the benefit as a lump-sum transfer at retirement. Tricks like these would not only make the solution trivial, but more importantly, contradict the purpose of a social security system. ${ }^{6}$

An individual's lifetime utility, $v$, is the sum of his or her utility when active and retired. If a worker of type $t$ retires at age $R$, then he or she receives utility $u(1-\tau)$ for $R$ years and $w(b)$ for $(t-R)$ years, and the lifetime utility is

$$
v=R u(1-\tau)+(t-R) w(b) .
$$

The individual's preference for leisure is reflected in that $u(\cdot)$ and $w(\cdot)$ are different functions. For simplicity, we may assume that $u(x)=w(x)-\varepsilon, \varepsilon>0$, where $\varepsilon$ is the disutility of labor. The only restriction we make regarding $u(\cdot)$ and $w(\cdot)$ is that for all $\tau \in(0,1)$,

$$
w(0)-w^{\prime}(0) \tau<u(1-\tau)<w(1)-w^{\prime}(1)(\tau+1) .
$$

This (technical) condition ensures that an internal solution to the first-best problem exists (see Theorem 0 in the next section).

The government's goal is to design an optimal pension system, $\langle b(R), \tau\rangle$, maximizing an additive concave social welfare function, $\sum_{t} \psi\left(v_{t}\right) f_{t}$, where $f_{t}$ is the relative frequency of individuals with expected lifespan $t .{ }^{7}$

We can split the government's problem into two problems: the optimal choice of $b(R)$ for a fixed $\tau$, and the optimal choice of $\tau$, given the optimal $b(R)$ schedules for all $\tau$. In the analysis below (Sections 3 and 4), we will focus on the first issue, the determination of $b(R)$ given $\tau$, because this is the part where asymmetric information on individual lifespans plays any role. In our model, the social security tax rate is the same for everyone, thus it is only the benefit-retirement age function that enables the mechanism designer to sort individuals according to their expected lifespans. ${ }^{8}$ Since the social planner cannot observe the individuals' ex-

\footnotetext{
${ }^{6}$ For example, in the latter case, the individual would have to get private life annuities for the lump-sum transfer at retirement, which would be equally prone to adverse selection due to the asymmetry of information regarding lifespans.

${ }^{7}$ In the present version we consider a discrete-type model. Note also that adding up utilities of individuals with different lifespans means that we consider the total utilities of a cohort or the whole population.

${ }^{8}$ As opposed to our model, in reality the personal income tax rate depends on the age and the benefit (cf., Diamond and Mirrlees, 1978), but we neglect this issue.
} 
pected lifespan, the benefit rule has to be (Bayesian) incentive compatible. We will not impose a participation constraint as the system is mandatory for the agents. However, we will have a cross-sectional budget balance constraint, as usual in the optimal income taxation literature.

\section{Solution to the First-Best Problem}

In this section, we derive the optimal benefit-retirement age schedule (given $\tau$ ) under the assumption that every worker's expected lifespan is commonly observable. The result will serve as a benchmark for the second-best solution, which is the subject of the next section.

Due to complete information, the social planner (the mechanism designer) can design a first-best retirement plan by assigning a retirement age, $R_{t}$, and a yearly benefit, $b_{t}$, to a worker with expected lifespan $t$, for all $t$. Without loss of generality, we require that $R_{t} \leq t$. We will denote the lifetime utility of a worker with expected lifespan $t$ by $v_{t}$, where $v_{t}=\left[u(1-\tau)-w\left(b_{t}\right)\right] R_{t}+w\left(b_{t}\right) t$. Types (expected lifespans) range from $S$ to $T$ (both integers). Since $\tau$ is given for now, we denote $\bar{u} \equiv u(1-\tau)$.

Given $\tau$, the social planner maximizes the frequency-weighted sum of an increasing and concave function $\psi$ of the individual utilities subject to a feasibility constraint:

$$
\max _{\left(b_{t}, R_{t}\right)_{t}} \sum_{t=S}^{T} \psi\left(v_{t}\right) f_{t}
$$

subject to

$$
\begin{aligned}
v_{t} & =\left[\bar{u}-w\left(b_{t}\right)\right] R_{t}+w\left(b_{t}\right) t \\
0 & \leq \sum_{t=S}^{T}\left[\left(\tau+b_{t}\right) R_{t}-t b_{t}\right] f_{t},
\end{aligned}
$$

We call this the first-best problem. Assign $\lambda$ to the aggregate budget constraint and write the Lagrangian as

$$
L^{*}=\sum_{t=1}^{T} \psi\left(\left[\bar{u}-w\left(b_{t}\right)\right] R_{t}+w\left(b_{t}\right) t\right) f_{t}+\lambda \sum_{t=1}^{T}\left\{\left(\tau+b_{t}\right) R_{t}-t b_{t}\right\} f_{t} .
$$

The first order conditions are

$$
\begin{aligned}
& L_{b}^{* \prime}=\psi^{\prime}\left(v_{t}\right) w^{\prime}\left(b_{t}\right)\left(t-R_{t}\right)+\lambda\left(R_{t}-t\right)=0 \Leftrightarrow \psi^{\prime}\left(v_{t}\right) w^{\prime}\left(b_{t}\right)=\lambda, \\
& L_{R}^{* \prime}=\psi^{\prime}\left(v_{t}\right)\left[\bar{u}-w\left(b_{t}\right)\right]+\lambda\left(\tau+b_{t}\right)=0 .
\end{aligned}
$$


The solution to the first order conditions implies,

Theorem 0. In the first-best schedule, $\left(b_{t}^{*}, R_{t}^{*}\right)_{t=1}^{T}$, the benefit is invariant with respect to the expected lifespan, $b_{i}^{*} \equiv b^{*}$, where $b^{*}$ satisfies

$$
\bar{u}-w\left(b^{*}\right)+w^{\prime}\left(b^{*}\right)\left(\tau+b^{*}\right)=0 .
$$

This equation has a solution in $b^{*}$ by assumption (2). Note that $\bar{u}<w\left(b^{*}\right)$, and the solution to (3) is unique because the derivative of the left hand side is negative.

Under utilitarianism (i.e., if $\psi(v) \equiv v$ ), there may exist several solutions for $R_{t}^{*}$ that satisfy $R_{t}^{*} \leq t$ and the social budget balance constraint with $b_{t}^{*} \equiv b^{*}$. One particular utilitarian first-best solution is autarky (budget balance holding for every type separately), where

$$
R_{t}^{A}=\frac{b^{*}}{\tau+b^{*}} t, \quad t=S, \ldots, T .
$$

If $\psi$ is strictly concave, then $R_{t}^{*}$ for $t=S, \ldots, T$ are determined by the aggregate budget balance constraint together with the first order conditions,

$$
\psi^{\prime}\left(v_{t}\right)=\frac{\lambda}{w^{\prime}\left(b^{*}\right)}=\psi^{\prime}\left(v_{s}\right), \quad s, t \in\{S, \ldots, T\},
$$

where $v_{t}=\left[\bar{u}-w\left(b^{*}\right)\right] R_{t}+w\left(b^{*}\right) t$. Clearly, $s<t$ if and only if $R_{t}^{*}<R_{s}^{*}$. Typically, the first-best scheme differs from autarky.

Note that neither autarky nor the first-best solution under strictly concave $\psi$ is incentive compatible. That is, the social planner cannot implement these retirement schemes by asking the workers to report their expected lifespans and assigning them to different retirement ages accordingly. This is so because $R_{t}^{A}$ (or $R_{t}^{*}$ ) is strictly increasing in $t$, while $b_{t}^{*}$ is constant. Hence those workers who expect to live longer have no incentive to reveal this information as it may only extend their working years without increasing their benefit. Formally, for $R_{t}^{*}$ to be incentive compatible with $b_{t}^{*}=b^{*}, R_{t}^{*}$ has to be constant, too.

What are the restrictions that incentive compatibility imposes on a feasible mechanism, in general? We turn to the problem of finding the second-best (optimal and incentive compatible) retirement mechanism in the next section.

\section{Optimal Retirement Mechanism under Asym- metric Information}

Now we return to the model's original informational assumption and assume that individuals have private information regarding their expected lifespans, and only 
the distribution of these data is commonly known. Therefore, the optimal benefitretirement schedule will have to satisfy incentive compatibility constraints, as usual in (Bayesian) mechanism design.

Incentive compatibility of $\left(b_{t}, R_{t}\right)_{t=S}^{T}$ means that type $t$ prefers to choose $\left(b_{t}, R_{t}\right)$ from the schedule. The adjacent IC constraints are, for $t=S, \ldots, T-1$,

$$
\begin{aligned}
v_{t} & \geq\left[\bar{u}-w\left(b_{t+1}\right)\right] R_{t+1}+w\left(b_{t+1}\right) t=v_{t+1}-w\left(b_{t+1}\right) \\
v_{t+1} & \geq\left[\bar{u}-w\left(b_{t}\right)\right] R_{t}+w\left(b_{t}\right)(t+1)=v_{t}+w\left(b_{t}\right) .
\end{aligned}
$$

which can be rewritten more compactly as,

$$
v_{t}+w\left(b_{t}\right) \leq v_{t+1} \leq v_{t}+w\left(b_{t+1}\right), \quad \text { for } t=S, \ldots, T-1 .
$$

Note that by monotonicity of $w(\cdot), b_{t}$ is weakly increasing. It is easy to show that non-adjacent IC constraints do not bind, hence we can ignore them.

Given $\tau$, the problem of the social planner now becomes,

$$
\max _{\left(b_{t}, R_{t}\right)_{t}} \sum_{t=S}^{T} \psi\left(v_{t}\right) f_{t}
$$

subject to

$$
\begin{aligned}
v_{t} & =\left[\bar{u}-w\left(b_{t}\right)\right] R_{t}+w\left(b_{t}\right) t \\
0 & \leq \sum_{t=S}^{T}\left[\left(\tau+b_{t}\right) R_{t}-t b_{t}\right] f_{t}, \\
v_{t}+w\left(b_{t}\right) & \leq v_{t+1} \leq v_{t}+w\left(b_{t+1}\right), \quad t=S, \ldots, T-1 .
\end{aligned}
$$

We will call this the social planner's "second-best" problem, and analyze its solution in the rest of the paper. Since the qualitative results are markedly different depending on whether the social welfare function is utilitarian or strictly concave, we will deal with these two cases in two separate subsections.

\subsection{Solution under Utilitarianism}

Assume (in this subsection only) that the social welfare function is utilitarian, that is, $\psi(v) \equiv v$. Suppose that

$$
R^{*} \equiv \frac{b^{*}}{\tau+b^{*}} \sum_{t=S}^{T} t f_{t}<S,
$$

that is, the first-best retirement age of a worker with an average expected lifespan is lower than the lower bound on the distribution of $t$. (This is a reasonable assumption for old-age pension.) Then we have the following surprising result. 
Theorem 1. If the social welfare function is utilitarian and (5) holds, then the socially optimal benefit plan is completely inflexible,

$$
b(R)=\left\{\begin{array}{cc}
0 & \text { for } R<R^{*} \\
b^{*} & \text { for } R \geq R^{*} .
\end{array}\right.
$$

Moreover, the second-best solution attains the first-best.

Proof. The benefit rule in (6) corresponds to the mechanism $b_{t} \equiv b^{*}, R_{t} \equiv R^{*}$ for all $t$. This scheme is incentive compatible because it is constant (the worker's allocation does not depend on his announced type). But it is also a first-best solution because the retirement benefit is set accordingly $\left(b_{t} \equiv b^{*}\right)$, and the mechanism satisfies aggregate budget balance, $\sum_{t=S}^{T}\left[\left(\tau+b^{*}\right) R^{*}-t b^{*}\right] f_{t}=0$. Note also that by $(5), R^{*} \leq t$ for all $t$.

The result of the theorem extends appropriately when (5) does not hold (to be added in subsequent versions).

\subsection{Optimal Rule under Strictly Concave $\psi$}

Suppose that $\psi(\cdot)$ is strictly concave. The optimal utilititarian benefit rule, given in equation (6), is still feasible and incentive compatible, but it is no longer socially optimal. Evaluated according to any strictly concave social welfare function, there is too much redistribution from short-lived individuals to long-lived ones. In other words, the allocation where all workers have to retire at the same age with the same benefits appears to be "unfair" to a society that puts larger weights on the utilities of unlucky individuals (those who were born with lousy genes and will not live very long).

In order to solve the second-best problem under strictly concave $\psi$, we first rewrite the second-best problem with Mirrlees' (1986, Section 6) method of change of variables. Denote retirement age by

$$
R\left(v_{t}, b_{t}, t\right)=\frac{w\left(b_{t}\right) t-v_{t}}{w\left(b_{t}\right)-u}
$$

and the lifetime net contribution (or balance) of type $t$ by

$$
z\left(v_{t}, b_{t}, t\right)=\left(\tau+b_{t}\right) R\left(v_{t}, b_{t}, t\right)-t b_{t} .
$$

Also, let us (temporarily) ignore the "upward" incentive constraints, $v_{t+1} \leq v_{t}+$ $w\left(b_{t+1}\right)$, for $t=S, \ldots, T-1$. The transformed problem becomes

$$
\max _{\left(b_{t}, v_{t}\right)_{t}} \sum_{t=S}^{T} \psi\left(v_{t}\right) f_{t}
$$


subject to

$$
\begin{aligned}
\sum_{t=S}^{T} z\left(v_{t}, b_{t}, t\right) f_{t} & \geq 0, \\
v_{t+1}-v_{t}-w\left(b_{t}\right) & \geq 0, \quad t=S, \ldots, T-1 .
\end{aligned}
$$

Assign $\lambda$ to the first constraint and $\left(\mu_{t}\right)_{t}$ to the second group of constraints. Then the Lagrangian can be written as

$$
L=\sum_{t=S}^{T}\left[\psi\left(v_{t}\right)+\lambda z\left(v_{t}, b_{t}, t\right)\right] f_{t}+\sum_{t=S}^{T-1} \mu_{t}\left(v_{t+1}-v_{t}-w\left(b_{t}\right)\right) .
$$

Application of a standard technique yields

Theorem 2. The necessary first-order conditions for the solution of the secondbest problem are for $t=S, \ldots T$,

$$
\begin{aligned}
& L_{b}^{\prime}=\lambda z_{b}^{\prime}\left(v_{t}, b_{t}, t\right) f_{t}-\mu_{t} w^{\prime}\left(b_{t}\right)=0 \\
& L_{v}^{\prime}=\left[\psi^{\prime}\left(v_{t}\right)+\lambda z_{v}^{\prime}\left(v_{t}, b_{t}, t\right)\right] f_{t}-\mu_{t}+\mu_{t-1}=0, \\
& \left.L_{\mu}^{\prime}=v_{t+1}-v_{t}-w\left(b_{t}\right) \geq 0, \quad \mu_{t} \geq 0 \quad \text { (w/c.s. }\right), \\
& \left.L_{\lambda}^{\prime}=\sum_{t=S}^{T} z\left(v_{t}, b_{t}, t\right) f_{t} \geq 0, \quad \lambda \geq 0 \quad \text { (w/c.s. }\right),
\end{aligned}
$$

where $\mu_{S-1}=0, \mu_{T}=0$ and $v_{T+1} \in \mathbb{R}$.

By the definition of $z\left(v_{t}, b_{t}, t\right)$, the partial derivatives that appear in the first order conditions are,

$$
\begin{aligned}
z_{v}^{\prime}\left(v_{t}, b_{t}, t\right) & =-\frac{\tau+b_{t}}{w\left(b_{t}\right)-\bar{u}} \\
z_{b}^{\prime}\left(v_{t}, b_{t}, t\right) & =\frac{v_{t}-t \bar{u}}{\left[w\left(b_{t}\right)-\bar{u}\right]^{2}}\left\{\left(\tau+b_{t}\right) w^{\prime}\left(b_{t}\right)-\left[w\left(b_{t}\right)-\bar{u}\right]\right\} .
\end{aligned}
$$

Apart from the improbable corner solution, Theorem 2 implies the following

Corollary. In the optimal solution to the second-best problem, $b_{T}=b^{*}$ (first-best). If $\psi$ is strictly concave, then $b_{t}<b^{*}$ for all $t<T$, that is, all individuals except the ones with the longest expected lifespan receive lower than first-best pension benefits.

Remark. Our formulation uses discrete time, and hence one cannot expect a smooth benefit function. A continuous time formulation would yield conditions analogous to equations (7)-(10), and result in a continuous benefit function. We chose the discrete time formulation because in the numerical simulations we have to use a discrete approximation anyway. 


\section{Algorithm for Computing the Second-Best}

Since the solution to the system of nonlinear equations in Theorem 2 is quite difficult, and analytical results may be hard (or in some cases, impossible) to obtain, it is natural to turn to numerical simulations. Numerical computations with realistic parameter values may also shed light on the quantitative properties of the optimal benefit rule, and various questions (e.g., regarding the magnitudes of endogenous variables, their sensitivity to parameter changes, etc.) can be answered.

In this Section we outline an appropriate algorithm to find a solution of the system of nonlinear equations in Theorem 2. In Section 6 we report the results of simulations using this algorithm.

The problem can be solved recursively as follows. Assume that parameters $\bar{u}$, $\tau$ and $\left(f_{t}\right)_{t=1}^{T}$ are given.

1. Take an appropriate initial value for $\lambda$. This parameter is to be calibrated to make equation (10) hold in the end.

2. Start with an initial value for $v_{T}$ (e.g., the static optimum) and set $\mu_{T}=0$. From equation (7), get $b_{T}=b^{*}$.

3. Iteration. For all $t$, if the vector $\left(v_{t+1}, b_{t+1}, \mu_{t+1}\right)$ is given, then obtain $\left(v_{t}, b_{t}, \mu_{t}\right)$ as follows. Determine $\mu_{t}$ from equation (8) at $(t+1)$. Then compute $\left(b_{t}, v_{t}\right)$ from equations (7) and (9).

4. The previous step results in a sequence $\left(v_{T}, b_{T}, \mu_{T}\right), \ldots,\left(v_{S}, b_{S}, \mu_{S}\right)$, based on which $\mu_{S-1}$ can be determined from equation (8) at $t=S$. Adjust $v_{T}$ and repeat step 3 until $\mu_{S-1}=0$ holds.

5. Finally, adjust $\lambda$ and repeat steps $2-4$ until budget balance (equation 10) holds.

By varying $\tau$ and recomputing the optimal schedule, one can determine the optimal contribution (or tax) rate. Intuitively it is clear that if $\tau$ is low, then $b_{t}$ is also low and $R_{t}$ is high; on the other hand, if $\tau$ is high, then $b_{t}$ is acceptable but $R_{t}$ is low, for $t=S, \ldots, T$. 


\section{Simulation}

We turn to the description of our simulations. Assume that from the point of view of the government, the individuals' expected lifespans (starting from entering the workforce at age 20) are between $S=49$ and $T=59$. Let the pensioner's felicity function be of CRRA-type, $w(x)=\theta-x^{\sigma} / \sigma, 1-\sigma$ being the coefficient of relative risk aversion and denote the disutility of labor by $\varepsilon$.

We shall define a CRRA family of social welfare functions as follows: $\psi(v)=$ $v^{\rho} / \rho, \rho \leq 1$ and call $\rho$ the social welfare inequality index. The lower the index, the more weight is given to individuals with lower utilities, i.e., the more egalitarian is the system.

We report several runs of simulation below.

Run 1. First we assume that the lifespans are uniformly distributed: $f_{t} \equiv 1$. We set $\theta=4.1, \sigma=-0.5$ and $\varepsilon=1.398$. In the first-best case, the optimality of the tax rate implies that the worker's consumption is equal to pensioner's. (This is a consequence of the assumption that the worker's and the pensioner's felicity functions only differ in an additive constant $\varepsilon$.) Therefore let the payroll tax rate be $\tau=0.2$. Then $\bar{u}=4.1-0.8^{-0.5}-1.398=0.466$, and the first-best retirement benefit is $b^{*}=0.8$. Note that our choice means that one's 0.8 unit consumption as an active worker is equivalent to a 0.303 unit consumption as a pensioner. The difference is due to the increased consumption of leisure after retirement. Observe that the longest-lived person should retire having worked $R_{T}=T b^{*} /\left(\tau+b^{*}\right)=47.2$ years (at the age of 67.2 years).

By Theorem 1, if the social welfare function is utilitarian (a la Harsanyi), then the optimal incentive compatible pension system will send everybody to retirement after working 43.2 years with the first-best benefits. This cannot be improved even under complete information regarding $t$ and differs from autarky only in that longlived individuals are subsidized by short-lived individuals.

Run 2. In Runs 2-5 we consider a social welfare function with $\rho=-1$. We display the optimal benefit, retirement age, and net contribution as functions of individual lifespans in Figures 1.a-c, respectively. We also display the optimal and the traditional (fair) benefit-retirement age functions in Figures 1.d, central concepts of the pension incentives.

An additional 10 years in lifespan implies almost 3 years additional service and about $17 \%$ points additional benefit, which is $21 \%$ on a relative scale. Note that the lifetime net contributions vary from 3.1 units for the shortest-lived to -3.5 units for the longest-lived. Note the retirement age-benefit function is mildly nonlinear. In order to measure the nonlinearity of the benefit function, we calculate the accrual rate $\alpha_{t}=\left[b_{t+1}-b_{t}\right] /\left[R_{t+1}-R_{t}\right], t=S, \ldots, T-1$. 
Figure 1.a

Optimal lifespan - benefit function

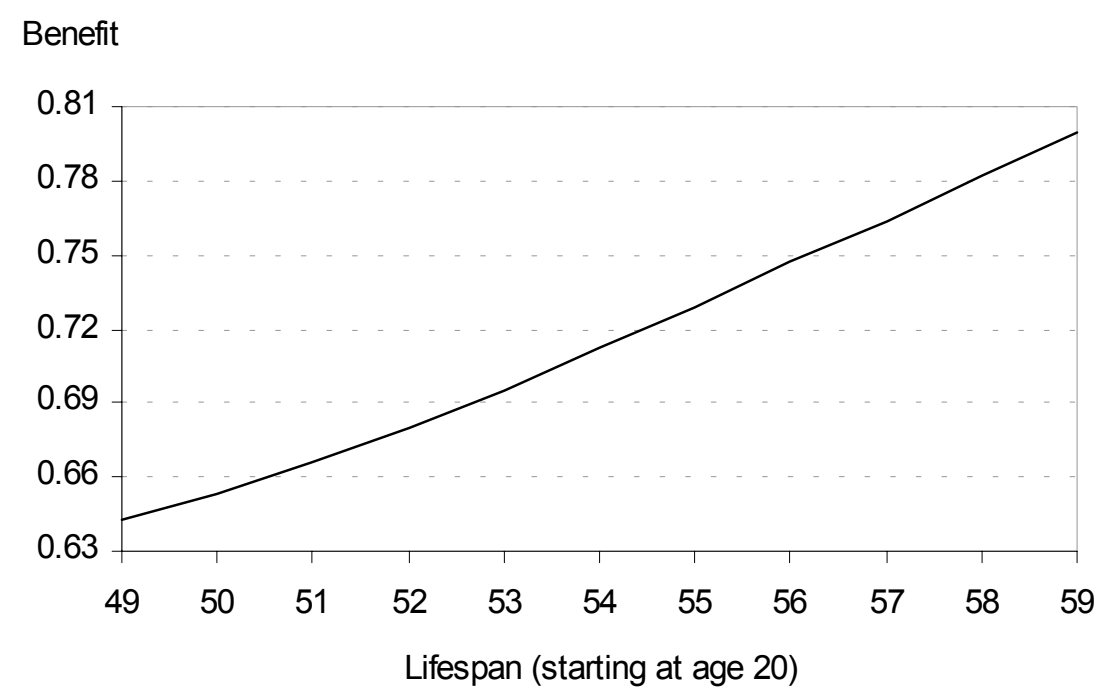

Figure 1.b

Optimal lifespan - retirement year function

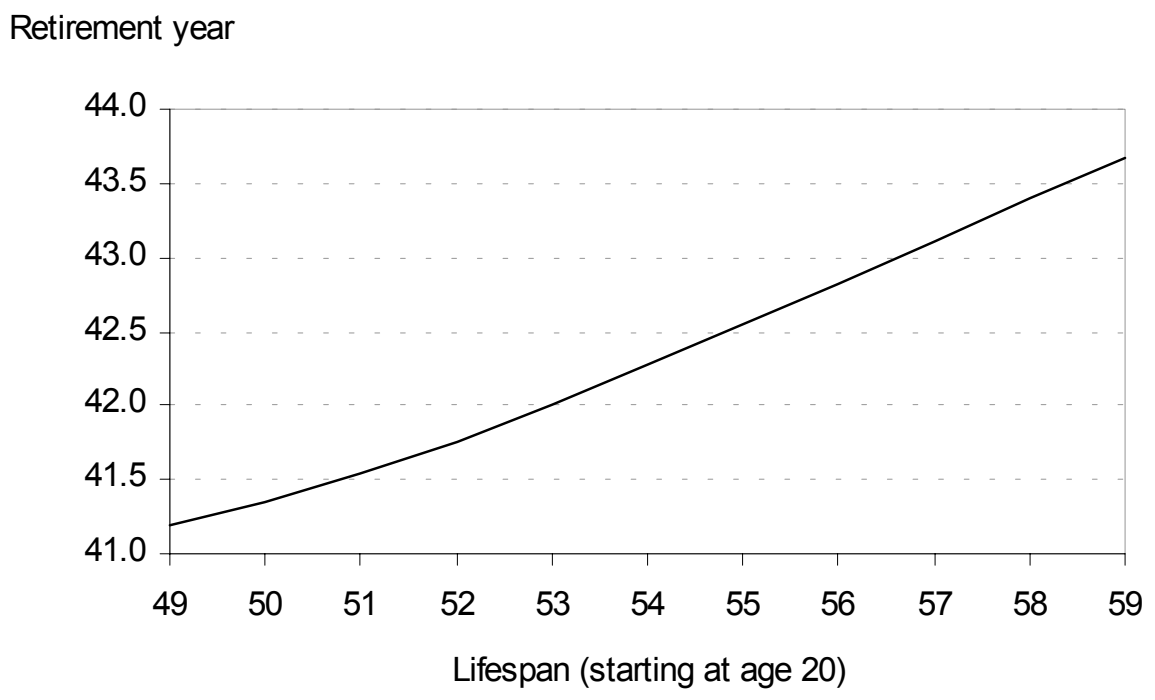


Figure 1.c

Contribution balance as a function of lifespan

\section{Balance}

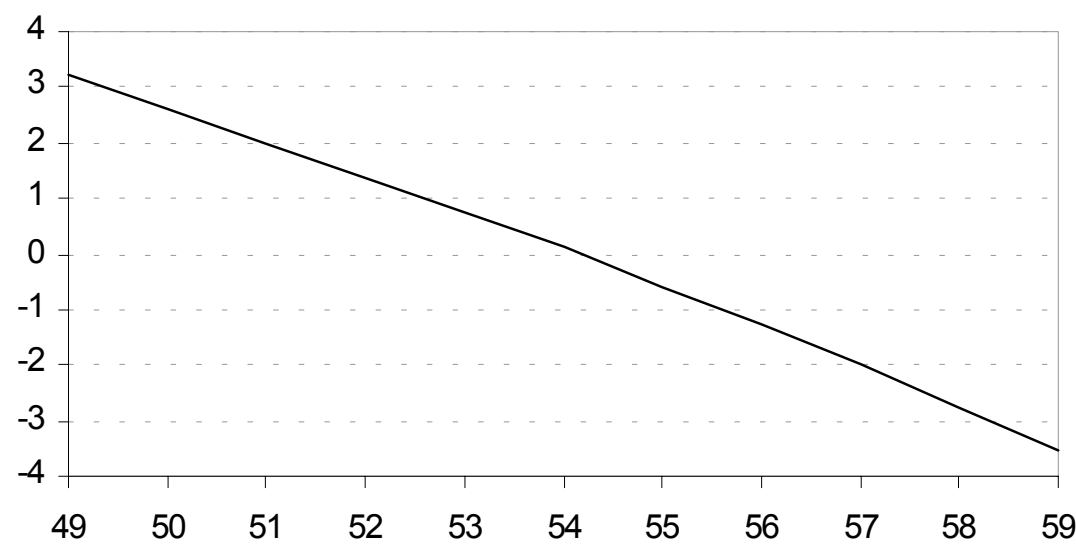

Lifespan (starting at age 20)

Figure 1.d

Optimal and naïve/fair benefit rules
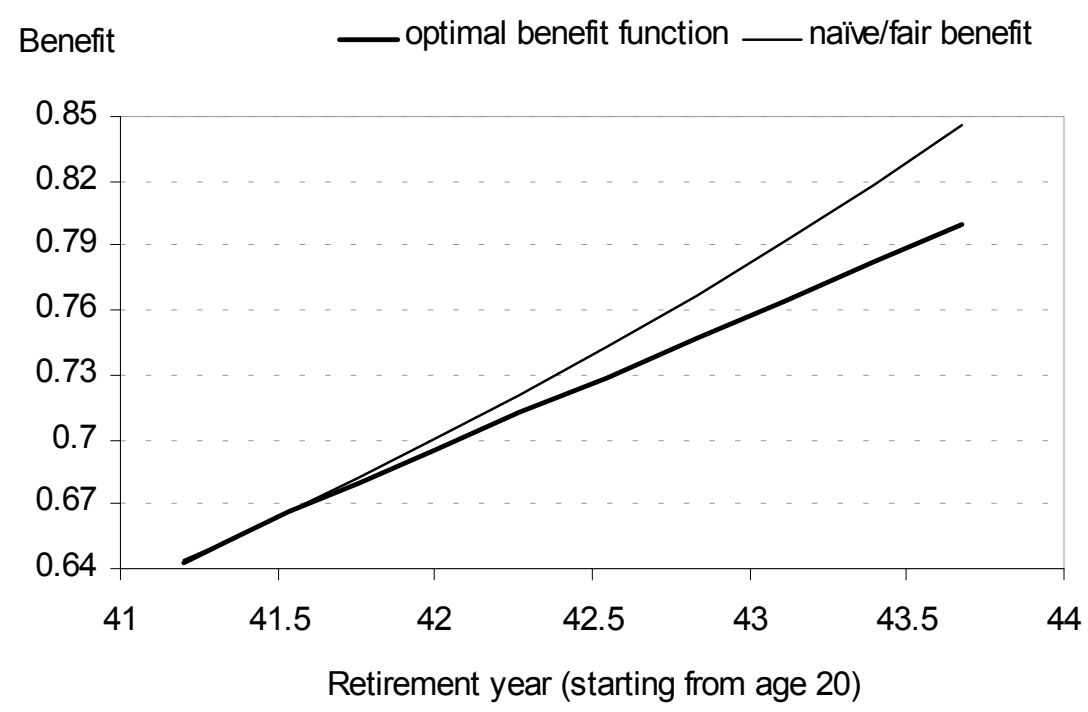
Run 3. Increasing $\sigma$ to -0.45 , in the optimal pension system, the three shortest-lived types retire at the same (legally prescribed) minimal age $R_{\min }=41.9$ and they receive the same minimal benefit $b_{\min }=0.69$. (This "bunching" is a standard feature of optimal mechanism design. See, for example, Mirrlees (1971) where workers of the lowest ability are excluded from work and given a minimum benefit.) For the remaining eight types, the incentive constraints apply to: the longer somebody lives, the later s/he retires. Decreasing $\sigma$ to -0.55 , one obtains approximately linear retirement age-benefit function. Further decreasing $\sigma$ to -0.6 , one obtains a convex retirement age-benefit function.

Run 4. To simplify the calculations, we compress our 11 types into 3 types, with lifespans 51, 54 and 57 years, but retain a uniform distribution on these three points. Table 1 illustrates the characteristics of Run 4.

Table 1. Optimal characteristics for the compressed model

\begin{tabular}{lllll}
\hline Lifespan & Benefit & Retirement age & Balance & Slope of benefit \\
$t$ & $b_{t}$ & $R_{t}$ & $z_{t}$ & $\alpha_{t}$ \\
\hline 51 & 0.666 & 41.437 & 1.916 & 0.060 \\
54 & 0.733 & 42.539 & 0.109 & 0.065 \\
57 & 0.800 & 43.573 & -2.024 & - \\
\hline
\end{tabular}

Note that the compressed model only approximates the original model, for example, the concave benefit function turns into a convex one.

Run 5. Until now we have fixed the payroll tax rate. However, the optimal choice of this rate is a central issue of pension economics. Let us try to determine the socially optimal $\tau$ in our compressed model. Figure 2c shows that the social welfare function is rather flat at the autark optimum (20\%). We display the optimal benefit and retirement age for the minimal, medium, and maximal ages as functions of the contribution rate in Figures 2.a-b, respectively. The benefits slightly increase or stagnate and the retirement ages sharply diminish, as the tax rate rises. 
Figure 2.a

Tax rate and optimal benefits

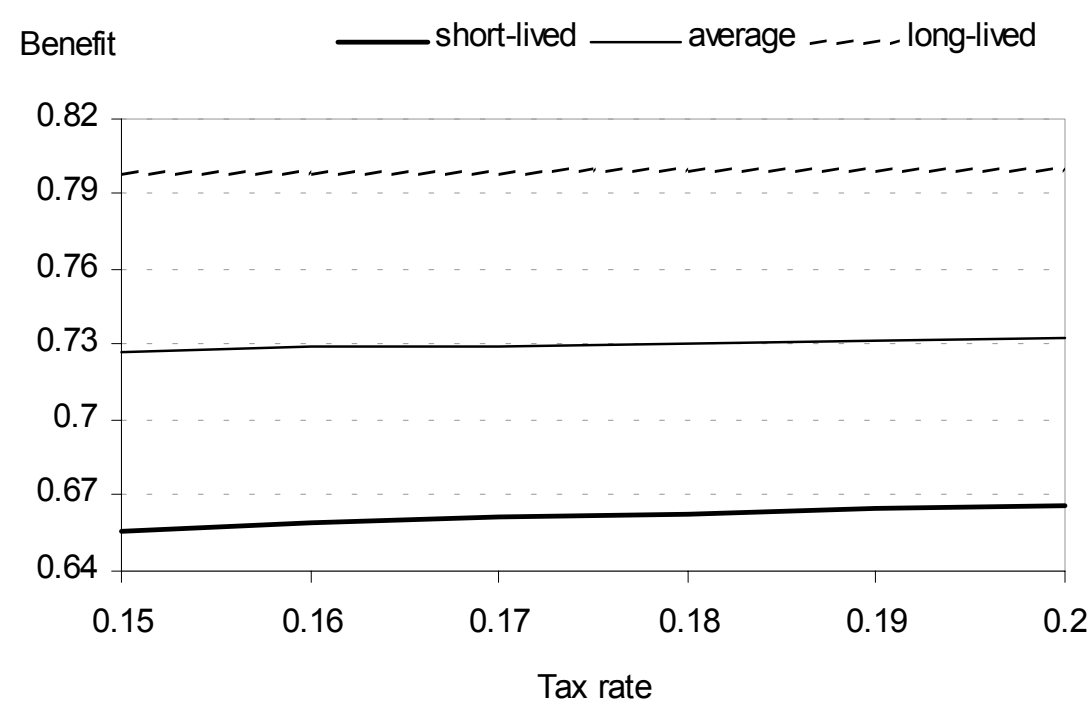

Figure 2.b

Tax rate and optimal retirement year

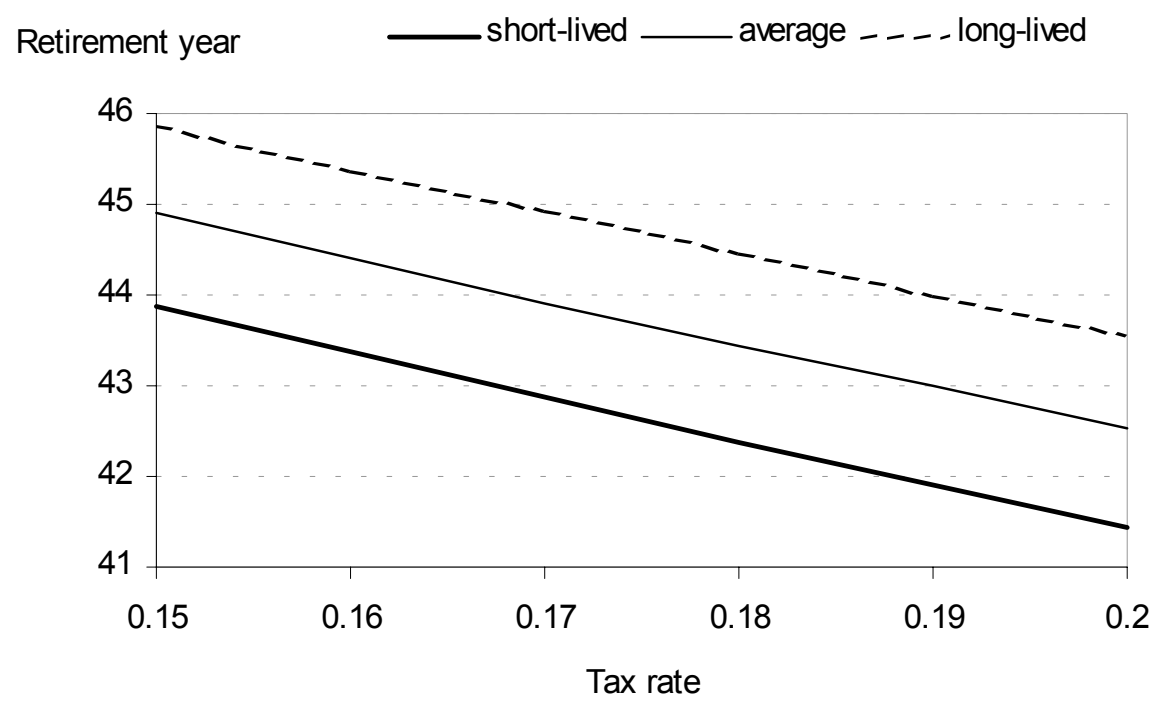


Figure 2.c

Tax rate and welfare

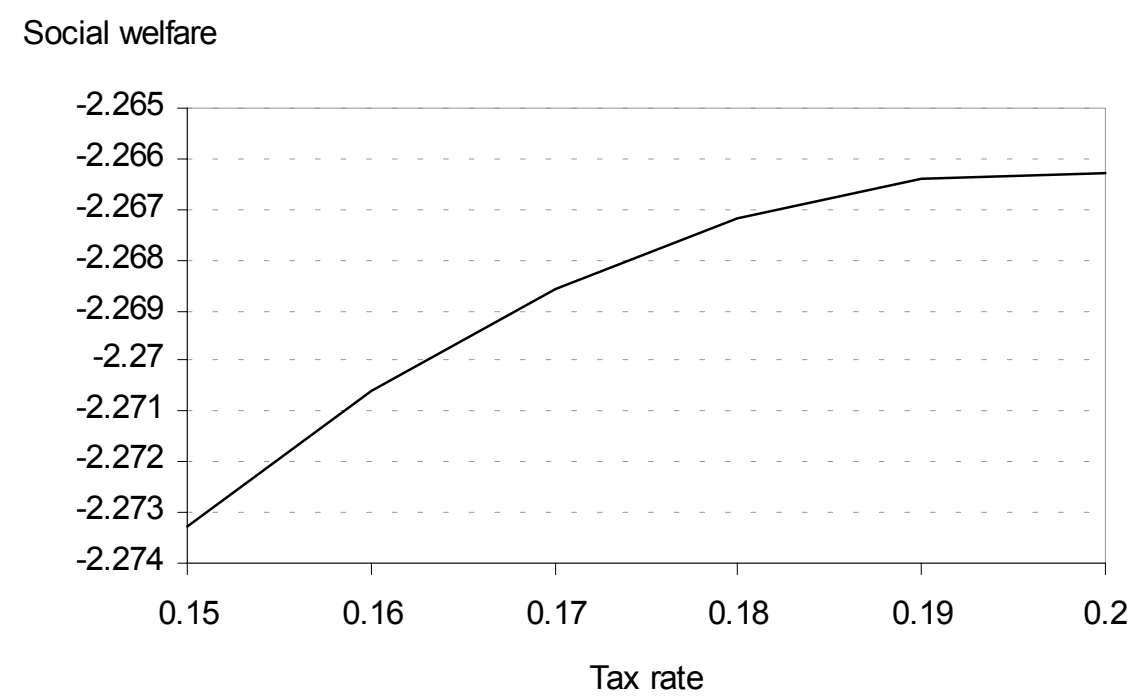

\section{Conclusion}

In this paper, we have applied standard techniques of mechanism design to determine optimal pension benefit rules, in the case where individuals have private information regarding their own expected lifespan. We have characterized the optimal contribution and benefit functions by a set of necessary first-order conditions. We developed a practical algorithm to compute the optimal incentives and filled the program with realistic data. Our simulations, however, glossed over many important details, including the heterogeneity of labor disutilities and the interaction of the pension system with income taxation. Moreover, we have only provided numerical (and not yet analytical) confirmation for some important conjectures, in particular, that the lifetime net contribution and the ratio of benefit to the length of employment are increasing functions of the individual lifespan. Further research will have to clarify our exploratory results. 


\section{References}

[1] Arrow, J. K. and Intrilligator, M. D. eds. (1986): Handbook of Mathematical Economics, Vol. III., Elsevier Science Publisher.

[2] Börsch-Supan, A. (2001): "The German Retirement Insurance System", Börsch-Supan and Miegel, eds., 13-38.

[3] Börsch-Supan, A., and Miegel, M. eds. (2001): Pension Reform in Six Countries, Berlin, Springer.

[4] Coile, C., and Gruber, J. (2000): "Social Security Incentives for Retirement", NBER WP 7651.

[5] Diamond, P. (2001): "Taxation, Incomplete Markets and Social Security", Munich Lectures, Cambridge, MA, MIT Press.

[6] Diamond, P., and Mirrlees, J. (1978): "A Model of Social Insurance with Variable Retirement", Journal of Public Economics 10:295-336.

[7] Diamond, P., and Mirrlees, J. (1986), "Payroll-Tax Financed Social Security with Variable Retirement", Scandinavian Journal of Economics 88:25-50.

[8] Friedmann, B. M. and Warshawski, M. J. (1990): "The Cost of Annuities: Implications for Saving Behavior and Bequests", Quarterly Journal of Economics 105:135-154.

[9] Gruber, J., and Orszag, P. (1999): "What to Do About the Social Security Earning Test", Issue in Brief \#1, Center for Retirement Research, Boston College.

[10] Gruber, J., and Wise, D. A., eds. (1999): Social Security and Retirement Program Around the World, Chicago, Chicago University Press.

[11] Guegano, Y. (2000): Cessation d'activité, départ en retrait et décisions individuelles: vers la neutralité actuarielle de barémand de retraites et une plus grande liberté de choix, Paris, Caisse des Dépôts et Consignations.

[12] Mas-Collel, A., Whinston, M. D., and Green, R. J. (1995): Microeconomic Theory, Oxford, Oxford University Press.

[13] Mirrlees, J. A. (1971): "An Exploration in the Theory of Optimum Income Taxation", Review of Economic Studies 38:175-208.

[14] Müller, K., Ryll, A., and Wagener, H-J., eds. (1999): Transformation of Social Security: Pensions in Central-Eastern Europe, Heidelberg, Physica. 
[15] Samwick, A. (1998): "New Evidence on Pensions, Social Security and the Timing of Retirement", Journal of Public Economics 70:207-236.

[16] Simonovits, A. (1999): "The New Hungarian Pension System and its Problems", Muller et al., eds. 211-230.

[17] Simonovits, A. (2001): "Employment Length, Leisure and Pension: Incentives with Limits", Budapest, CEU Department of Economics, Working Paper 3.

[18] Simonovits, A. (2002): "Designing Optimal Linear Contribution and Benefit Functions for Flexible Retirement", Budapest, CEU Department of Economics, typescript.

[19] Stock, J. and Wise, D. (1990): "Pensions, the Option Value of Work, and Retirement", Econometrica 58:1151-1180.

[20] Waldron, H. (2001): "Links between Early Retirement and Mortality", ORES Working Paper 93, Division of Economic Research, SS Administration. 